\title{
Antibiograms from community-acquired uropathogens in Gulu, northern Uganda - a cross-sectional study
}

\author{
Charles $O$ Odongo ${ }^{1 *}$, Denis A Anywar ${ }^{2}$, Kenneth Luryamamoi ${ }^{3}$ and Pancras Odongo ${ }^{4}$
}

\begin{abstract}
Background: Urinary tract infections (UTI) are common in clinical practice and empirical treatment is largely employed due to predictability of pathogens. However, variations in antibiotic sensitivity patterns do occur, and documentation is needed to inform local empirical therapy. The current edition of the Uganda Clinical Guidelines recommends amoxicillin or cotrimoxazole as choice drugs for empirical treatment of community-acquired UTI. From our clinical observations, we suspected that this recommendation was not effective in our setting. In order to examine validity, we sought to identify bacteria from community-acquired infections and determine their susceptibility against these antibiotics plus a range of potentially useful alternatives for treatment of UTI.

Methods: A cross-sectional study of mid-stream urine collected from 339 symptomatic patients over a three-month period at Gulu regional referral hospital. Qualitative culture and identification of bacteria and antibiotic sensitivity testing using the modified Kirby-Bauer disk diffusion method was done. Participants' demographic and clinical characteristics were collected using a standard form. Results were analyzed by simple proportions among related variables and confidence intervals computed using binomial exact distribution.
\end{abstract}

Results: Eighty two cultures were positive for UTI. Staphylococcus spp (46.3\%) and Escherichia coli (39\%) were the most common pathogens. There was high resistance to cotrimoxazole (73.2\%), nalidixic acid (52.4\%) and amoxicillin (51.2\%). The most favorable antibiograms were obtained with gentamicin, amoxicillin-clavulanate and levofloxacin where $85.4 \%, 72.0 \%, 67.1 \%$ of isolates respectively, were either sensitive or intermediate. Only $51 \%$ of isolates were sensitive to ciprofloxacin.

Conclusion: There was high resistance to most antibiotics tested in this study. The recommendations contained in the current edition of the Uganda Clinical Guidelines are not in tandem with antibiotic sensitivity pattern of uropathogens seen in our setting. Amoxicillin-clavulanate or gentamicin should be considered for replacement of amoxicillin and cotrimoxazole for empirical treatment of UTI in our setting.

Keywords: Antibiograms, Antibiotic resistance, Uropathogens, Empirical treatment, Uganda

\section{Background}

Urinary tract infections (UTI) are a common medical problem encountered in medical practice. Females are more prone to infection than males, a phenomenon explained by their short urethra and its anatomical proximity to the anal orifice $[1,2]$. Because uropathogens largely originate from colonic flora [3], they are easy to

\footnotetext{
*Correspondence: codongo76@gmail.com

'Department of Pharmacology \& Therapeutics, Faculty of Medicine, Gulu University, P.O. box 166, Gulu, Uganda

Full list of author information is available at the end of the article
}

predict. This is the rationale for empirical treatment in community-acquired urinary tract infections (CA-UTI) $[1,4]$. However, empirical treatment limits opportunities for surveillance of antibiotic resistance among pathogens that cause community-acquired UTI. If regularly updated to match changing susceptibility patterns, empirical treatment is also a convenient strategy for effective resource utilization. This is especially true in developing countries where resource constraints mean that it is often impractical to routinely perform antibiotic sensitivity tests [5]. Reports of uropathogens resistant to previously effective

\section{Biomed Central}


antibiotics have emerged globally in recent years [6-18]. The situation is especially dire in Africa where irrational antibiotic practices are common [18]. Variations in antibiotic resistance patterns are known to occur across different geographical regions, even within the same country $[16,19]$. Such variations must be well documented so as to inform local empirical treatment as well as foster rational antibiotic use.

The current edition of the national treatment guidelines in Uganda recommends the use of amoxicillin or cotrimoxazole for empirical treatment of CA-UTI [20]. However, based on our clinical experience at Gulu regional hospital, we suspected that resistance to these antibiotics was possibly high. Therefore, continued empirical use was likely to increase chances of treatment failure, leading to unnecessary patient suffering and increased healthcare costs in the long run. The broad aim of this study was to examine the validity of the current recommendations for empirical treatment of CA-UTI as per the national guidelines. Specifically, we set out to identity uropathogens from community-acquired infections at Gulu regional hospital and thereafter, determine their resistance profiles against the currently recommended antibiotics. In addition, we sought to determine resistance profile against a range of potentially useful alternatives for treatment of CA-UTI in our setting.

\section{Methods}

\section{Study design}

This was a cross-sectional study employing both qualitative and quantitative methods. All outpatients ( $\geq 18 \mathrm{yrs})$ with symptoms suggestive of a UTI were consecutively recruited into the study. Symptoms of interest included supra-pubic pain, a burning sensation while voiding (dysuria), urine frequency and urge incontinence. A predesigned standard form was used to record relevant socio-demographic and medical history information, as well as important clinical and laboratory findings. Participants were asked to provide an on-the-spot urine sample for investigation to determine true cases of UTI. Bacterial isolates from true infections were identified and subjected to antibiotic susceptibility testing using the Kirby-Bauer disk diffusion method [21]. The recommended antibiotics, plus a range of potentially useful alternatives were included in the tests which were performed at the microbiology laboratory of the Faculty of Medicine, Gulu University.

\section{Urine sample collection}

Mid-stream (clean-catch) urine samples were collected by participants under the supervision of nurses and midwives serving as research assistants. These were trained on how to instruct and guide urine collection as per standard methods [22]. Mindful of the cultural sensitivity of the procedure, we employed research assistants who were conversant with the local Luo dialect and cultural experience. Participants were led into a clean toilet facility and asked to wash their hands with soap and water prior to urine collection. They were handed a well-labeled, sterile, wide mouth urine container $(50 \mathrm{ml})$ and accordingly instructed. Labeling consisted of participant study number, sex, and date of urine collection. Briefly on the collection method, the uncircumcised male was told to retract the foreskin on the glans penis prior to collection. He was asked to void the first bit of urine into the toilet pan before collecting the mid-portion (starting approximately $2 \mathrm{~s}$ from beginning of flow) and then finally voiding the last bit again into the toilet pan. He then closed the bottle and passed it on to the research assistant for storage. In the case of females, the research assistant gently separated the labia minora and wiped the area around the urethral orifice (from front to back) using sterile gauze dipped in normal saline. This procedure was repeated with the labia held apart before collection of urine as described above. All samples were immediately stored in an ice box and transported to the laboratory within three hours of collection.

\section{Determination of true infection and identification of uropathogens}

Urine samples were registered in the record book and given serial laboratory numbers. The consideration of a sample as 'true UTI' was arrived at in a two-stage screening process involving microscopic enumeration of urine leucocytes followed by quantitative urine culture. This approach was adopted because neither approach alone was considered sufficient to conclusively label a case as 'true UTI'. For instance, urinary schistosomiasis or prior antibiotic use, were likely to confound findings from the above methods respectively. First, one microliter $(1 \mu \mathrm{L})$ of a well mixed urine sample was aspirated into an improved Neubauer counting chamber (Marienfeld$\mathrm{GmbH}$, Germany) and examined with a light microscope under X 400 magnification. A finding of at least 5 and 10 leucocytes per microliter in males and females respectively was considered UTI basing on previous recommendations [23]. All samples that were positive by this criterion were further subjected to urine culture in the second stage. A $10 \mu \mathrm{L}$ plastic loop was used to pick a well mixed urine sample which was plated for quantitative culture on $\mathrm{Nu}$ trient Agar (BioMerieux/Hi Media) and CLED Agar (BD Diagnostic Systems, Germany) prepared according to standard methods [24]. The use of two media was aimed at isolating all possible bacteria as well as using their unique colony growth characteristics to aid identification. All plates were inverted and incubated at $35^{\circ} \mathrm{C}( \pm 1)$ for 18 to 24 hours with each resultant colony considered to represent $100 \mathrm{CFU} / \mathrm{ml}$. A cutoff point of $10^{5} \mathrm{CFU} / \mathrm{ml}$ was 
considered significant growth as long as the culture was pure [24]. All urine samples that had significant leucocyturia and thereafter significant bacterial growth were considered true UTI. In addition, samples that had significant leucocyturia but less than $10^{5} \mathrm{CFU} / \mathrm{mL}$ were considered true UTI if there was a positive history of antibiotic use prior to presenting at the hospital. Unique colony growth characteristics, gram staining and a battery of biochemical tests were used to identify uropathogens. These included sugar fermentation using TSI agar, litmus milk decolorization, citrate utilization, indole production, the methyl red test, as well as catalase, coagulase and urease tests. All tests were performed according to standard methods described elsewhere [24].

\section{Preparation of Mueller-Hinton agar and antibiotic susceptibility assays}

Antibiotic susceptibility was done on Mueller-Hinton II agar (Oxoid, UK) according to the Kirby-Bauer method modified in accordance with current guidelines from the Clinical \& Laboratory Standards Institute (CLSI) [25]. Preparation of Mueller-Hinton II agar was by dissolving $38 \mathrm{~g} / \mathrm{L}$ as per manufacturer's recommendations. All agar preparations were fully dissolved and autoclaved at $121^{\circ} \mathrm{C}$ for 15 minutes. After sterilization, $25 \mathrm{ml}$ was gently poured onto each sterile petri dish ( $90 \mathrm{~mm}$ diameter) placed on a horizontal work top and allowed to cool to room temperature. This corresponds to an agar depth of $4 \mathrm{~mm}$ [24]. The plates were then inverted and stored in sealed plastic bags at $4-8^{\circ} \mathrm{C}$ until use, in any case not longer than 15 days. Quality control of each batch was ensured by testing Enterococcus faecalis (ATCC 2922) against cotrimoxazole. Prior to inoculation and placement of antibiotic disks, sterility of each plate was ensured by overnight incubation $\left(35 \pm 1^{\circ} \mathrm{C}\right)$ in which no growth occurred.

Three to five morphologically similar colonies of each organism (aged 18-24 h) were touched with a sterile loop and inoculated in $4 \mathrm{ml}$ of peptone water (BDH Chemicals Ltd) prepared according to manufacturer's recommendations. The peptone water was incubated at $36^{\circ} \mathrm{C}$ for 2 to 5 hours until turbid, and standardized to 0.5 McFarland nephelometer prepared by dissolving 1 gram of barium chloride in $100 \mathrm{ml}$ of sulfuric acid using normal saline. The entire surface of agar was inoculated by swabbing and allowed to dry for 3 to 5 minutes before aseptically placing 4 antibiotic disks per plate. The following commercially prepared antibiotic disks (Oxoid, UK) were used: nitrofurantoin $(50 \mu \mathrm{g})$, nalidixic acid $(30 \mu \mathrm{g})$, ciprofloxacin $(5 \mu \mathrm{g})$, levofloxacin $(5 \mu \mathrm{g})$, amoxicillin $(10 \mu \mathrm{g})$, cephalexin $(30 \mu \mathrm{g})$, amoxicillinclavulanate $(20 / 10 \mu \mathrm{g})$, cotrimoxazole $(25 / 125 \mu \mathrm{g})$, gentamicin $(10 \mu \mathrm{g})$, azithromycin $(15 \mu \mathrm{g})$ and oxacillin $(10 \mu \mathrm{g})$. Well set plates were incubated in a dry oven maintained at $35^{\circ} \mathrm{C}\left( \pm 1^{\circ} \mathrm{C}\right)$. Inhibition zone diameters were read at $18 \mathrm{~h}$ for all organisms except for Staphylococcus which was read at $24 \mathrm{~h}$. Clear zone diameters were measured to the nearest millimeter using a millimeter ruler under natural light. Internal quality control was ensured by incubating Staphylococcus aureus (ATCC 25923) and Escherichia coli (ATCC 25922) strains under the same conditions.

\section{Data entry and analysis}

Laboratory entries were made in a laboratory book each day. The data was constantly checked for completeness and cleaned during the study. Each measurement of the inhibition zone diameter was interpreted as 'sensitive', 'intermediate' or 'resistant' according to CLSI standard interpretative charts [25]. At the end of collection, data was double-entered into Epidata ${ }^{\circ}$ computer program, validated and analyzed by simple percentages among related variables. For all proportions obtained, confidence intervals set at $95 \%$ level of significance were computed using binomial exact distribution.

\section{Ethical considerations}

The study was performed in accordance with the Helsinki Declaration and was approved by the Institutional Review Board of the Faculty of Medicine, Gulu University (reference no. GU/IRB/03/06/11). Permission to conduct the study was granted by the Uganda $\mathrm{Na}-$ tional Council for Science and Technology. Informed consent was obtained in writing from each participant. The investigators ensured that participants were handled in a professional and culturally sensitive manner and patient confidentiality was observed throughout the study. At the earliest opportunity, clinically important information was forwarded to the attending clinician to ensure optimum patient care.

\section{Results}

\section{General patient characteristics}

Out of 339 samples analyzed over a period of three months (June to August, 2011), only 82 met our inclusion criteria for true UTI. Three samples (3.7\%) were obtained from males while seventy nine $(96.3 \%)$ came from females. Fourteen women $(17.7 \%)$ were pregnant and one male participant had clinical findings consistent with prostatic hypertrophy. Sixty nine participants (20.4\%) reported antibiotic use prior to presenting at the hospital. Most of them (72\%) had self-medicated and none had received a full antibiotic course by the time of presentation to the hospital. Table 1 gives a summary of the demographic and clinical characteristics of patients investigated in the study. 
Table 1 Demographic and clinical characteristics of outpatients with urinary tract infection at Gulu regional hospital $(n=82)$

\begin{tabular}{|c|c|c|c|}
\hline Parameter & $\begin{array}{l}\text { Males } \\
(n=3)\end{array}$ & Females $(n=79)$ & Total (\%) \\
\hline Mean age in years (range) & $46(37-59)$ & $23(18-70)$ & \\
\hline $\begin{array}{l}\text { Pregnancy status among } \\
\text { participants }\end{array}$ & N/A & $\begin{array}{l}\text { Not pregnant }=65 \\
\text { Pregnant }=14\end{array}$ & 79 \\
\hline \multicolumn{4}{|l|}{ Presenting symptoms ${ }^{\mathrm{a}}(\%)$} \\
\hline Increased urine frequency & - & 85 & N/A \\
\hline Supra pubic pain/discomfort & - & 77 & N/A \\
\hline Dysuria & - & 68 & N/A \\
\hline Urge incontinence & - & 55 & N/A \\
\hline $\begin{array}{l}\text { History of recurrent symptoms } \\
\text { (in past } 6 \text { months) }\end{array}$ & 0 & 3 & 3 \\
\hline $\begin{array}{l}\text { Immune suppression } \\
\text { symptoms }\end{array}$ & 0 & 0 & 0 \\
\hline $\begin{array}{l}\text { Neurological disease affecting } \\
\text { micturition }\end{array}$ & 0 & 0 & 0 \\
\hline Renal angle pain/tenderness & 0 & 0 & 0 \\
\hline Prostatic enlargement & 1 & N/A & \\
\hline Recent catheterization & 0 & 0 & 0 \\
\hline Positive urine sugar & 0 & 0 & 0 \\
\hline $\begin{array}{l}\text { Recent antibiotic use } \\
(2 \text { weeks })^{\mathrm{b}}\end{array}$ & 0 & 69 & $69(20.4)$ \\
\hline 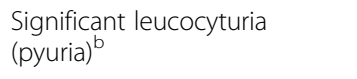 & 3 & 115 & $118(34.8)$ \\
\hline At least $10^{5} \mathrm{CFU} / \mathrm{mL}^{\mathrm{c}}$ & 3 & 64 & $67(56.8)$ \\
\hline
\end{tabular}

Key: N/A, Not applicable; CFU, Colony forming units. ${ }^{\text {a }}$ calculations only done for female participants as males were too few for meaningful results.

${ }^{b}$ recorded from all patients having any symptom suggestive of a UTI $(n=339)$.

${ }^{c}$ test performed only on patients with significant leucocyturia $(n=118)$.
Identity and proportions of uropathogens isolated As shown in Table 2, Staphylococcal species $(n=38$, 46.3\%) caused majority of UTI. This was followed by Escherichia coli $(\mathrm{n}=32,39 \%)$. Other uropathogens isolated include Enterococcus faecalis ( $\mathrm{n}=6,7.3 \%)$, Klebsiella pneumoniae $(\mathrm{n}=4,4.9 \%)$ and Proteus mirabilis $(\mathrm{n}=2$, 2.4\%). Among the Staphylococcal species isolated, 28 were identified as S. saprophyticus while 9 were identified as S. aureus. There was one case of S. epidermidis isolated from the male patient with prostatic hypertrophy.

\section{Antibiotic susceptibility and resistance profiles}

Regarding antibiotic susceptibility assays, the zone diameters with all control strains were within published limits. As presented in Table 2, there was widespread resistance among all uropathogens to cotrimoxazole, amoxicillin, nitrofurantoin and nalidixic acid. A summary of the relative proportions of susceptibility and resistance profiles from all uropathogens against each antibiotic is presented in Table 3 along with their confidence intervals set at 95\% level of significance. When sensitive and intermediate readings were combined, the most favorable profiles were obtained with gentamicin, amoxicillin-clavulanic acid and levofloxacin for which $85.4 \%, 72.0 \%$ and $67.1 \%$ of isolates respectively, were considered susceptible (Table 3). Of the pathogens isolated from male participants, there was one case each, of Escherichia coli, Staphylococcus aureus and Staphylococcus epidermidis. For the entire study, this was the only incidence of Staphylococcus epidermidis. This participant also had symptoms of prostatic hypertrophy. Interestingly as shown in Table 4, this organism had marked sensitivity to most antibiotics tested except nalidixic acid and nitrofurantoin.

Table 2 Susceptibility profile of uropathogens isolated from symptomatic outpatients at Gulu regional hospital, northern Uganda $(\mathbf{n}=\mathbf{8 2})$

\begin{tabular}{|c|c|c|c|c|c|c|c|c|c|c|c|c|c|c|c|}
\hline \multirow{2}{*}{$\begin{array}{l}\text { Uro-isolates } \\
\text { Antibiotic disks }\end{array}$} & \multicolumn{3}{|c|}{ Staphylococcus spp. $n=38$} & \multicolumn{3}{|c|}{ E. coli $n=32$} & \multicolumn{3}{|c|}{ Klebsiella spp. $n=4$} & \multicolumn{3}{|c|}{ P. mirabilis $n=2$} & \multicolumn{3}{|c|}{ E. faecalis $n=6$} \\
\hline & $\mathrm{S}$ & I & $\mathbf{R}$ & $\mathbf{S}$ & I & $\mathbf{R}$ & $\mathrm{S}$ & I & $\mathbf{R}$ & $\mathbf{S}$ & I & $\mathbf{R}$ & $\mathrm{S}$ & I & $\mathbf{R}$ \\
\hline Nitrofurantoin $(50 \mu \mathrm{g})$ & 8 & 14 & 16 & 10 & 5 & 17 & 0 & 1 & 3 & 0 & 0 & 2 & 4 & 0 & 2 \\
\hline Nalidixic acid $(30 \mu \mathrm{g})$ & 4 & 10 & 24 & 13 & 6 & 13 & 0 & 2 & 2 & 0 & 0 & 2 & 2 & 2 & 2 \\
\hline Cotrimoxazole $(25 / 125 \mu \mathrm{g})$ & 5 & 5 & 28 & 5 & 5 & 22 & 0 & 0 & 4 & 0 & 0 & 2 & 2 & 0 & 4 \\
\hline Amoxicillin $(10 \mu \mathrm{g})$ & 16 & 6 & 16 & 10 & 3 & 19 & 0 & 1 & 3 & 0 & 2 & 0 & 2 & 0 & 4 \\
\hline Amoxi/clav (20/10 $\mu \mathrm{g})$ & 26 & 3 & 9 & 10 & 10 & 12 & 0 & 4 & 0 & 0 & 2 & 0 & 3 & 1 & 2 \\
\hline Cephalexin $(30 \mu g)$ & 16 & 13 & 9 & 5 & 8 & 19 & 3 & 1 & 0 & 0 & 0 & 2 & 2 & 0 & 4 \\
\hline Ciprofloxacin $(5 \mu \mathrm{g})$ & 24 & 0 & 14 & 19 & 5 & 8 & 3 & 1 & 0 & 2 & 0 & 0 & 4 & 0 & 2 \\
\hline Levofloxacin $(5 \mu \mathrm{g})$ & 29 & 2 & 7 & 13 & 9 & 10 & 2 & 2 & 0 & 2 & 0 & 0 & 3 & 1 & 2 \\
\hline Gentamicin $(10 \mu \mathrm{g})$ & 24 & 7 & 7 & 26 & 1 & 5 & 4 & 0 & 0 & 2 & 0 & 0 & 6 & 0 & 0 \\
\hline Azithromycin $(15 \mu \mathrm{g})$ & 6 & 9 & 23 & 10 & 17 & 5 & 4 & 0 & 0 & 1 & 1 & 0 & 5 & 1 & 0 \\
\hline Oxacillin $(10 \mu \mathrm{g})^{*}$ & 7 & 0 & 2 & - & - & - & - & - & - & - & - & - & - & - & - \\
\hline
\end{tabular}

Key: S, Sensitive; I, Intermediate; $R$, Resistant; * tested on Staphylococcus aureus only $(\mathrm{n}=9)$. 
Table 3 Relative proportions of susceptibility and resistance profiles from all uropathogens isolated from outpatients at Gulu regional hospital, northern Uganda $(n=82)$

\begin{tabular}{lllll}
\hline Antibiotic (disc potency) & Sensitive $\mathbf{( 9 5 \% ~ C l )}$ & Intermediate $\mathbf{( 9 5 \% ~ C l )}$ & Total ${ }^{\text {a }}$ (\%) & Resistant (95\% Cl) \\
\hline Nitrofurantoin $(50 \mu \mathrm{g})$ & $24(19.5-40.4)$ & $20(15.6-35.1)$ & $44(53.7)$ & $38(35.3-57.7)$ \\
Nalidixic acid $(30 \mu \mathrm{g})$ & $19(14.7-33.8)$ & $20(15.6-35.1)$ & $39(47.6)$ & $43(41.1-63.6)$ \\
Cotrim. $^{\text {b }}(25 / 125 \mu \mathrm{g})$ & $12(7.8-24.2)$ & $10(6.0-21.3)$ & $22(26.8)$ & $60(56.2-82.4)$ \\
Amoxicillin $(10 \mu \mathrm{g})_{\text {Amox-clav }}^{\mathrm{c}}(20 / 10 \mu \mathrm{g})$ & $29(25.1-46.7)$ & $11(6.9-22.7)$ & $40(48.8)$ & $42(39.9-62.4)$ \\
Cephalexin $(30 \mu \mathrm{g})$ & $39(36.4-58.9)$ & $20(15.6-35.1)$ & $59(72.0)$ & $23(18.7-39.1)$ \\
Ciprofloxacin $(5 \mu \mathrm{g})$ & $26(21.9-42.9)$ & $22(17.6-37.8)$ & $48(58.5)$ & $34(30.7-52.9)$ \\
Levofloxacin $(5 \mu \mathrm{g})$ & $36(33.0-55.3)$ & $6(2.7-15.2)$ & $42(51.2)$ & $40(37.6-60.1)$ \\
Gentamicin $(10 \mu \mathrm{g})$ & $44(42.3-64.7)$ & $11(6.9-22.7)$ & $55(67.1)$ & $27(22.9-44.2)$ \\
Azithromycin $(15 \mu \mathrm{g})$ & $62(57.4-84.4)$ & $8(4.3-18.3)$ & $70(85.4)$ & $12(7.8-24.2)$ \\
\hline
\end{tabular}

Key: ${ }^{\text {a }}$ sum of sensitive and intermediate readings, ${ }^{b}$ cotrimoxazole, $^{c}$ amoxicillin-clavulanic acid.

\section{Discussion}

This study revealed relatively high frequencies of resistance to most antibiotics tested. Resistance to cotrimoxazole, amoxicillin, nitrofurantoin and nalidixic acid were particularly alarming. This is consistent with our clinical observations as well as findings from other recent studies done in Uganda [14,26,27]. Such high levels of resistance are probably due to antibiotic misuse by poorly trained health workers as has been documented in many developing countries $[18,28,29]$. In addition, weak government regulation allows for the importation and sale of substandard drugs, often from unlicensed outlets. This encourages domiciliary self-medication practices that have become commonplace in Uganda [30,31]. Moreover, it is not uncommon for unqualified health workers to offer clients the option of purchasing small quantities of antibiotics. This leads to inadequate dosing resulting into sub-inhibitory tissue concentrations that facilitate selection of antibioticresistant strains. It has been observed that the motives for antibiotic misuse by health workers are similar to those for misuse by lay persons: to cut costs and act expeditiously to treat suspected bacterial infections [28].

The particularly high resistance to cotrimoxazole may be explained by additional factors common in our setting. These include the use of cotrimoxazole as prophylaxis among HIV positive patients [20] and the use of sulfadoxine-pyrimethamine (shares enzyme targets with cotrimoxazole) for routine malaria prophylaxis during pregnancy [20]. In light of these considerations, we strongly suspect that a similar resistance profile occurs in other parts of Uganda. Therefore, UTI treatment with cotrimoxazole is likely to fail, exposing patients to unnecessary distress and an increased risk of complications. Some authors have however questioned the predictive value of in-vitro resistance testing among uropathogens, especially for antibiotics that achieve urinary concentrations much higher than those tested in laboratory assays [6,32]. For instance, it has been reported that urine levels of trimethoprim and sulfamethoxazole are 35 and 3 times, respectively, the levels in serum [33]. In such cases, it is possible that even with apparent in-vitro resistance, successful cure may be realized. In the present context, this issue may require further investigation.

Nearly $50 \%$ of uropathogens $(40 / 82)$ were resistant to ciprofloxacin (Table 3). This is far above the $20 \%$ rate recommended for empirical use of antibiotics for community-acquired UTI [34,35]. Ironically, a 32\% resistance was found with levofloxacin yet this antibiotic has barely been used in our setting owing to prohibitive costs. A fluoroquinolone cross-resistance phenomenon may explain this finding since the two drugs also share an enzyme target. These findings are of great concern considering that fluoroquinolones are reserved for severe

Table 4 Susceptibility profiles of uropathogens isolated from male patients at Gulu regional hospital, northern Uganda ( $\mathrm{n}=3$ )

\begin{tabular}{|c|c|c|c|c|c|c|c|c|c|c|c|}
\hline Uropathogen & TS & $A X$ & $\mathrm{CL}$ & $\mathrm{NI}$ & NA & CIP & LEV & $\mathrm{CN}$ & AZM & AMC & $O X^{*}$ \\
\hline S. epidermid ${ }^{a}$ & $\mathrm{~S}$ & $S$ & S & $\mathrm{R}$ & $\mathrm{R}$ & $S$ & S & $\mathrm{S}$ & 1 & S & \\
\hline S. aureus & $\mathrm{R}$ & $\mathrm{R}$ & S & 1 & $\mathrm{R}$ & $\mathrm{R}$ & $\mathrm{R}$ & $\mathrm{S}$ & $\mathrm{R}$ & S & $\mathrm{S}$ \\
\hline E. coli & $R$ & $\mathrm{R}$ & 1 & $S$ & $S$ & $S$ & $\mathrm{R}$ & $R$ & $S$ & $\mathrm{R}$ & - \\
\hline
\end{tabular}

Key: S, Sensitive; I, Intermediate; $R$, Resistant; TS, Cotrimoxazole; AX, Amoxicillin; AZM, Azithromycin; CL, Cefalexin; NI, Nitrofurantoin; NA, Nalidixic acid; CIP, Ciprofloxacin; LEV, Levofloxacin; $C N$, Gentamicin; $A M C$, Amoxicillin-clavulanic acid; $O X$, Oxacillin, ${ }^{\text {a }}$ Staph. epidermidis was associated with prostatic hypertrophy, * tested on Staphylococcus aureus only. 
or complicated UTI in Uganda [20]. Our study found a $46 \%$ resistance to nitrofurantoin (38/82, Table 3) compared to that of Mwaka et al., where only $2 \%$ of isolates were reported resistant among non-pregnant women in Kampala [26]. This apparent disparity might have come from the use of nitrofurantoin disks of different potency (300 $\mu \mathrm{g}$ in Mwaka et al., and $50 \mu \mathrm{g}$ in ours). In addition, socio-demographic differences between the population in Kampala and Gulu (approximately 400 kilometers apart) might have contributed. Being urban and rural populations respectively, differences in lifestyles, occupation, culture, attitudes and literacy exist. These factors (along with genetics) are known to influence disease and health seeking patterns, and may explain geographical variations in antibiotic resistance even within the same country $[16,19]$.

The most favorable antibiograms were obtained with gentamicin and amoxicillin-clavulanic acid where a total of $85.4 \%$ and $72.0 \%$ of isolates respectively, were either sensitive or intermediate against all organisms (Table 3). Either of these antibiotics could replace the current choices for empirical treatment of community-acquired UTI in our setting. Gentamicin is quite affordable and is already available within our public hospitals. To mitigate toxicity concerns, our physicians have adopted the newer once daily dosing of gentamicin known to be safer yet as effective as multiple dosing schedules [36]. An important drawback however is the fact that gentamicin has to be administered exclusively by injection, and a move towards its adoption is likely to be material and labor intensive. We fear that a resource-constrained healthcare system like ours will be particularly sensitive to additional strain. On the other hand, the high cost of oral amoxicillin-clavulanate means that it may not be available to all those who need it within the public sector.

At $46.3 \%$, Staphylococcal species formed the majority of uropathogens isolated in our study. This was followed by Escherichia coli at 39\%. This pattern is slightly different from that seen in most literature, where Escherichia coli commonly predominates [6-13]. Our findings are however similar to those reported by Kyabaggu et al. [14], where Staphylococcal species (32\%) followed by Klebsiella (21\%) were the commonest uropathogens isolated among patients at a metropolitan hospital in Kampala. Two other studies done at Mulago national referral hospital in Kampala ranked Staphylococcal species second to Escherichia coli among leading causes of asymptomatic bacteriuria among pregnant and nonpregnant women $[26,27]$. In our study, most Staphylococcal infections were due to S. saprophyticus (28/38). This organism has generally been found to colonize the urinary tract of sexually active women $[37,38]$. Our findings may point in this direction and are implicitly supported by the young study population and the fact that
Uganda has one of the highest fertility rates in the world [39]. With a mean age 23 years, female participants in our study were much younger than female participants in a similar European study (mean age 51.6) published recently [40]. Looking at these two populations, differences in sexual patterns that may influence UTI etiology are likely to exist.

This study presents outpatient-based antibiograms of uropathogens isolated from consecutively selected participants presenting to Gulu regional hospital. This represents a fairer picture of antibiotic susceptibility profiles within this community than would be expected from inpatient-based (or laboratory-based) antibiograms. The latter are more likely to reflect a selection bias towards complicated UTI and therefore, to over-estimate resistance prevalence in a particular community [32]. In this study, the proportion of samples that turned out as true UTI was rather small $(82 / 339)$ compared to the participant number that were recruited with symptoms. The poor correlation between symptoms and positive diagnosis may be explained by the rampant tendency among patients to self-medicate and only visit hospitals when symptoms persist. In such cases, quantitative urine culture is likely to be less sensitive, leaving investigators with a diagnostic dilemma. Consequently, our decision to adhere to the $10^{5} \mathrm{CFU} / \mathrm{mL}$ cut-off value might have excluded a significant proportion of UTI cases. In addition, the decision to consider as contaminants, all suspected cases where two or more organisms were isolated might also have contributed to the low numbers observed. Nevertheless, we were able to isolate most species commonly associated with community-acquired UTI in reasonable proportions. As shown in Table 1, some urine samples with leucocyturia did not yield significant bacterial growth on quantitative culture. Further investigations revealed presence of yeast cells in these samples, suggesting a fungal infection. Some urine samples did not yield any significant findings using our criteria despite symptoms. We think these symptoms were due to obstetric or other gynecological diseases that the study did not set out to investigate.

\section{Conclusion}

Staphylococcal species and E. coli are major causes of community-acquired UTI in our setting. There is unacceptably high resistance to cotrimoxazole and amoxicillin among uropathogens isolated in our setting. Continued use of these drugs is likely to be associated with a high risk of treatment failure. The recommendations of the Uganda Clinical Guidelines, 2010 are not in tandem with the situation obtaining on the ground in Gulu district. There is need to formulate an appropriate hospital antibiotic policy for the treatment of UTI in our setting. In the meantime, clinicians should take these 
findings into account whenever prescribing empirically for UTI. We recommend that either gentamicin or amoxicillin-clavulanate be used for empirical treatment of UTI in our setting.

\section{Competing interests}

The authors declare that they have no competing of interests.

\section{Authors' contribution}

$\mathrm{COO}$ and DAA conceived the design of the study with contribution from $\mathrm{KL}$ and PO. COO and DAA were involved in training research assistants, data collection and clinical care. COO, DAA and KL performed the laboratory investigations. $\mathrm{COO}$ drafted the manuscript and DAA, KL and PO contributed to its revision. All authors read and approved the final manuscript.

\section{Acknowledgements}

This work was funded by Training Health Researchers into Vocational Excellence in East Africa (THRiVE) project under grant number 087540 from the Welcome Trust. The funders had no role in conception or execution of the study or manuscript preparation. We sincerely thank Dr. Nathan Onyachi of Gulu Regional Hospital for the support offered to us during planning and executing of the study. We also acknowledge the service offered by the following nurses and midwives; Akello Kevin Joyce, Ajok Sophie Becky, Drichiru Harriet Abaru and Atim Filder. We thank Mr. Okello Joseph for his tireless input in the laboratory work.

\section{Author details}

'Department of Pharmacology \& Therapeutics, Faculty of Medicine, Gulu University, P.O. box 166, Gulu, Uganda. ${ }^{2}$ Department of Biochemistry and Molecular Biology, Faculty of Medicine, Gulu University, Gulu, Uganda. ${ }^{3}$ Department of Medical Microbiology \& Immunology, Faculty of Medicine, Gulu University, Gulu, Uganda. ${ }^{4}$ Department of Internal Medicine, Faculty of Medicine, Gulu University, Gulu, Uganda.

Received: 19 December 2012 Accepted: 19 April 2013

Published: 29 April 2013

\section{References}

1. Hummers-Pradier E, Kochen MM: Urinary tract infections in adult general practice patients. Brit J Gen Pract 2002, 52:752-761.

2. McLaughlin SP, Carson CC: Urinary tract infections in women. Med Clin North Am 2004, 88:417-429.

3. Yamamoto S, Tsukamoto T, Terai A, Kurazono H, Takeda Y, Yoshida O: Genetic evidence supporting the fecal-perineal-urethral hypothesis in cystitis caused by Escherichia coli. J Urol 1997, 157:1127-1129.

4. Miller $L G$, Tang AW: Treatment of uncomplicated urinary tract infections in an era of increasing antibiotic resistance; a concise review for clinicians. Mayo Clin Proc 2004, 79:1048-1054.

5. WHO: Community-Based Surveillance of Antimicrobial Use and Resistance in Resource-Constrained Settings; report on five pilot projects. 20 Apia Avenue, 1211 Geneva, Switzerland: WHO Press; 2009.

6. Gupta K, Hooten TM, Stamm WE: Increasing antimicrobial resistance and the management of uncomplicated community-acquired urinary tract infections. Ann Int Med 2001, 135:41-50.

7. Sahm DF, Thornsberry C, Mayfield DC, Jones ME, Karlowsky JA: Multidrug resistant isolate of $\mathrm{E}$. coli: prevalence and patient demographics in the United States in 2000. Antimicrob Agents Chemother 2001, 45:1402-1406.

8. Karlowsky JA, Kelly LJ, Thornsberry C, Jones ME, Sahm DF: Trends in antimicrobial resistance among urinary tract isolates of Escherichia coli from female outpatients in the United States. Antimicrob Agents Chemother 2002, 46:2540-2545.

9. Andrade SS, Sader HS, Jones RN, Pareira AS, Pignatari ACC, Gales AC: Increased resistance to first-line agents among bacterial pathogens isolated from urinary tract infections in Latin America: time for local guidelines? Mem Inst Oswaldo Cruz 2006, 101:741-748.

10. Kurutepe S, Surucuoglu S, Sezgin C, Gazi H, Gulay M, Ozbakkaloglu B: Increasing antimicrobial resistance in Escherichia coli isolates from community acquired urinary tract infections during 1998-2003 in Manisa, Turkey. Japan J Infect Dis 2005, 58:159-161.
11. Shigemura K, Tanaka K, Adachi M, Yamshita M, Arakawa S, Fujisawa M: Chronological change of antibiotic use and antibiotic resistance in Escherichia coli causing urinary tract infections. I Infect Dis Chemother 2011, 17(5):646-651.

12. Obaskei-Ebor EE: Trimethoprim/Sulfamethoxazole resistance in E. coli and Klebsiella species of urinary isolates. Afr J Med Sci 1988, 17:175-180.

13. Mordi RM, Erah PO: Susceptibility of common urinary isolates to the commonly used antibiotics in a tertiary hospital in southern Nigeria. Afr $\rfloor$ Biotech 2006, 5:1067-1071.

14. Kyabagu D, Ejobi F, Olila D: The sensitivity to first-line antibiotic therapy of the common urinary tract bacterial infections detected in urine samples at a hospital in metropolitan Kampala (Uganda). Afr Health Sci 2007, 7:214-222.

15. Dada-Adegbola HO, Muili KA: Antibiotic susceptibility pattern of urinary tract pathogens in Ibadan, Nigeria. Afr J Med Sci 2010, 39:173-179.

16. Schito GC, Naber KG, Botto H, Palou J, Mazzei T, Gualco L: The ARSEC study: an international survey on the antimicrobial resistance of pathogens involved in uncomplicated urinary tract infections. Int J Antimicrob Agents 2009, 34(5):407-413.

17. De Backer D, Christiaens T, Heytens S, De Sutter A, Stobberingh EE, Verschraegen G: Evolution of Bacterial susceptibility pattern of Escherichia coli in uncomplicated urinary tract infections in a country with high antibiotic consumption: a comparison of two surveys with a 10 year interval. J Antimicrob Chemother 2008, 62(2):364-368.

18. Okeke IN, Laxminarayan R, Bhutta ZA, Duse AG, Jenkins P, O'Brien TF, Mendez PA, Klugman KP: Antimicrobial resistance in developing countries. Part I: recent trends and current status. Lancet Infect Dis 2005, 5(8):481-493.

19. Gupta K: Addressing antibiotic resistance. Dis Mon 2003, 49:99-110.

20. Ministry of Health and The Uganda National Drug Authority: Uganda Clinical Guidelines 2010. National Guidelines on Management of Common Disease Conditions. Kisubi, Uganda: Marianum Press Ltd; 2010.

21. Kirby WM, Bauer AW: Antibiotic susceptibility testing by a standardized single disk method. Am J Clin Path 1966, 45:493-496.

22. Thomson RB, Miller JM: Specimen collection, transport, and processing: bacteriology. In Manual of Clinical Microbiology. 8th edition. Edited by Murray PR, Baron EJ, Jorgensen JH, Pfaller MA, Yolken RH. Washington DC: American Society of Microbiology; 2003.

23. Strandberg K, Beermann B, Lonnerholm G: Diagnosis and Treatment of Urinary Tract Infections: recommendations from the expert group. Medical Products Agency: Uppsala, Sweden; 1990.

24. Cheesbrough M: District Laboratory Practice in Tropical Countries. Part 2. Microbiology. Doddington: Cambridge University Press; 2000.

25. Clinical Laboratory Standards Institute: Performance Standards for Antimicrobial disk susceptibility tests; Approved Standard 9th Edition. Document M2-A9. Wayne, PA: CLSI; 2006. 26: 1.

26. Mwaka AD, Mayanja-Kizza H, Kigonya E, Kaddu-Mulindwa D: Bacteriuria among adult non-pregnant women attending Mulago hospital assessment center in Uganda. Afr Health Sci 2011, 11:182-189.

27. Andabati $\mathrm{G}$, Byamugisha J: Microbial etiology and sensitivity of asymptomatic bacteriuria among ante-natal mothers in Mulago hospital, Uganda. Afr Health Sci 2010, 10:349-352.

28. Okeke IN, Adebayo L, Edelman R: Socioeconomic and behavioral factors leading to acquired bacterial resistance to antibiotics in developing countries. Emerg Infect Dis 1999, 5(1):18-27.

29. Kunin CM, Johansen KS, Worning AM, Daschner FD: Report on a symposium on use and abuse of antibiotics worldwide. Rev Infect Dis 1990, 12:12-19.

30. Ouma F: Uganda: Self-medication causing drug resistance. In The New Vision Newspaper, May 29, 2007. Edited by Kaija B, Kakande J. Uganda: New Vision Printing and Publishing Coporation; 2007:17.

31. Kyalimpa J: Health-Uganda: self-medication blamed for increased drug resistance. In: Inter Press Service News Agency, July 15 2011. www.ipsnews. net/2011/07/health-uganda-self-medication-blamed-for-increased-drugresistance. Accessed on November 22nd 2011

32. Stamm WE, Norrby SR: Urinary tract infections: disease panorama and challenges. J Infect Dis 2001, 183(1):1-4.

33. Patel RB, Welling PG: Clinical pharmacokinetics of cotrimoxazole (sulfamethoxazole-trimethoprim). Clin Pharmacokin 1980, 5:405-423.

34. Warren JW, Abrutyn E, Hebel JR, Johnson RJ, Schaeffer AJ, Stamm WE: Guidelines for antimicrobial treatment of uncomplicated acute bacterial cystitis and acute pyelonephritis in women. Clin Infect Dis 1999, 29:745-758. 
35. Naber KG, Bergman B, Bishop MC, Bjerklund-Johansen TE, Botto H, Lobel B: EAU guidelines for the management of urinary and male genital tract infections. Urinary Tract Infection (UTI) Working Group of the Health Care Office ( $\mathrm{HCO}$ ) of the European Association of Urology (EAU). Eur Urol 2001, 40(5):576-588.

36. Prins JM, Buller HR, Kuijper EJ, Tange RA, Speelman P: Once versus thrice daily gentamicin in patients with serious infections. Lancet 1993, 341:335-339.

37. Rupp ME, Soper DE, Archer GL: Colonization of the female genital tract with Staphylococcus saprophyticus. J Clin Microb 1992, 30(11):2975-2979.

38. Jordan PA, Iravani A, Richard GA, Baer H: Urinary tract infection caused by Staphylococcus saprophyticus. J Infec Dis 1980, 142(4):510-515.

39. Uganda total fertility rate: total fertility rank chart. www.indexmundi.com/ uganda/total_fertility_rate.html. Accessed on 19th February 2013.

40. Schmiemann G, Gagyor I, Hummer-Pradier E, Bleidorn J: Resistance profiles of urinary tract infections in general practice - an observational study. BMC Urol 2012, 12:33. doi:10.1186/1471-2490-12-33.

doi:10.1186/1471-2334-13-193

Cite this article as: Odongo et al: Antibiograms from communityacquired uropathogens in Gulu, northern Uganda - a cross-sectional study. BMC Infectious Diseases 2013 13:193.

\section{Submit your next manuscript to BioMed Central and take full advantage of:}

- Convenient online submission

- Thorough peer review

- No space constraints or color figure charges

- Immediate publication on acceptance

- Inclusion in PubMed, CAS, Scopus and Google Scholar

- Research which is freely available for redistribution 